\title{
Predictors of Survival Outcomes in Non-Metastatic Renal Cell Carcinoma in Latin America and Spain: A Multicentric Analysis
}

Stênio de Cássio Zequi ${ }^{\mathrm{a}, \mathrm{b}}$, Thiago Camelo Mourão ${ }^{\mathrm{a}, *}$, Max Moura de Oliveira ${ }^{\mathrm{c}}$, Maria Paula Curado $^{c}$, Guilhermo Gueglio ${ }^{d}$, Walter Henriques da Costa ${ }^{\mathrm{a}}$, Alvaro Zuñiga ${ }^{\mathrm{e}}$, Rubén Bengióf Carlos Scorticati ${ }^{\mathrm{g}}$, Francisco Rodriguez ${ }^{\mathrm{h}}$, Ana Maria Autran ${ }^{\mathrm{i}}$, Pablo Martínez ${ }^{\mathrm{j}}$, Carlos Amerik ${ }^{\mathrm{k}}$, Pablo Mingote ${ }^{\mathrm{l}}$, Fernando Pablo Secin ${ }^{\mathrm{m}}$, Ricardo Decia ${ }^{\mathrm{n}}$, Isabela Werneck da Cunha ${ }^{\mathrm{a}, \mathrm{b}}$, Gustavo Cardoso Guimarães ${ }^{\mathrm{o}}$, Sidney Glina ${ }^{\mathrm{p}}$, Joan Palou ${ }^{\mathrm{q}}$ and Diego Abreu ${ }^{\mathrm{n}}$

${ }^{a}$ A.C. Camargo Cancer Center, São Paulo, Brazil

${ }^{\mathrm{b}}$ National Institute for Science and Technology in Oncogenomics and Therapeutic Innovation, AC Camargo Cancer Center, São Paulo, São Paulo, Brazil

${ }^{\mathrm{c}}$ Department of Epidemiology and Statistics, International Research Center, A.C. Camargo Cancer Center, São Paulo, Brazil

${ }^{\mathrm{d}}$ Italian Hospital, Buenos Aires, Argentina

${ }^{\mathrm{e}}$ Pontifical Catholic University of Chile, Santiago, Chile

${ }^{\mathrm{f}}$ Urological Center Profesor Bengió, Cordoba, Argentina

${ }^{g}$ Clinics Hospital José de San Martín, Buenos Aires, Argentina

h Instituto Nacional de Ciencias Médicas y Nutrición Salvador Zubirán, Mexico City, Mexico

i Jiménez Díaz Foundation, Madrid, Spain

${ }^{\mathrm{j}}$ British Hospital, Buenos Aires, Argentina

${ }^{\mathrm{k}}$ German Hospital, Buenos Aires, Argentina

${ }^{1}$ Policlinico Neuquén, Neuquén, Argentina

${ }^{\mathrm{m}}$ Center for Medical Education and Clinical Research Norberto Quirno (CEMIC), Buenos Aires, Argentina

${ }^{\mathrm{n}}$ Department of Urology, Pasteur Hospital, Montevideo, Uruguay

${ }^{\circ}$ Surgical Oncology Coordinator, Beneficencia Portuguesa Hospital, São Paulo, Brazil

pABC Medical School, São Paulo, Brazil

${ }^{\mathrm{q}}$ Puigvert Foundation, Barcelona, Spain

\section{Abstract.}

Background: Renal cell carcinoma (RCC) is a lethal neoplasia. Data from Latin America are scarce, and the distinct ethnic origins of this population could affect predictive or prognostic factors.

Objective: We aim to describe a large cohort of non-metastatic renal cell carcinoma, identifying the demographic, clinical, and pathological prognostic factors for survival.

\footnotetext{
${ }^{*}$ Correspondence to: Thiago Camelo Mourão - Rua Antônio Prudente 211, Liberdade, São Paulo, Brazil. 01509-010. E-mail:
} 
Methods: We used a multi-institutional retrospective cohort involving 5,670 patients who underwent radical or partial nephrectomy across seven Latin American countries and Spain from 1980 to 2016. The variables were compared, and Kaplan-Meier curves were used to estimate the overall survival (OS) and cancer-specific survival (CSS).

Results: The clear cell subtype represented $66.7 \%$ of RCC, followed by chromophobe (13.7\%), papillary (5.2\%), and others $(14.4 \%)$. Furthermore, $72.3 \%$ of renal masses were $<7.0 \mathrm{~cm}$. The 5 -year OS and 10 -year OS rates were $86.1 \%$ and $69.5 \%$, respectively. The 5-year and 10-year CSS rates were $89.9 \%$ and $81.8 \%$, respectively. The demographic and clinical predicting factors for OS in the multivariate analysis were age (HR: 2.978), anemia (HR: 1.44), presence of symptoms at presentation (HR: 1.26), Karnofsky score $\leq 80$ (HR: 2.12), and ASA score $\geq 3$ (HR: 1.49). The pathological factors were nodal metastasis (HR: 2.14), peri-renal fat invasion (HR: 2.12), inferior vena cava invasion (HR: 1.61), histologic tumoral necrosis (HR: 1.69), and tumor size $>7 \mathrm{~cm}$ (HR: 1.64$)$.

Conclusions: Our findings agreed with those reported for some developed countries. We emphasize that ASA and peri-renal fat invasion as prognostic factors deserve further study. Information regarding microvascular invasion should be regularly incorporated in pathological reports.

Keywords: Renal cell carcinoma, Latin America, survival analysis, nephrectomy

\section{INTRODUCTION}

Renal cell carcinoma (RCC) is one of the most lethal urological malignancies. About one-third of cases will have metastasis at presentation, and about $20 \%-50 \%$ will progress to metastatic disease despite surgical treatment [1-3]. Prognostic factors have been mainly described in series from North America and Europe, which have ethnic origins distinct from those of the Latin American population. In 2019, the American Cancer Society estimated 73,820 new cases of RCC and 14,770 deaths in the USA [4].

Latin America (LA) is a large developing area with people of multiracial and multicultural backgrounds, consisting of indigenous natives, European and Asian immigrants, and Africans. The number of new cases of RCC has risen both in the USA and LA, with a higher proportion of smaller lesions $[5,6]$. Mortality has been stabilized with a slight decrease in recent years, particularly in developed countries. However, mortality is still rising in many developing areas $[7,8]$. According to GLOBOCAN/IARC (International Agency for Research on Cancer), the highest mortality rates adjusted for age in LA occur in Uruguay, Argentina, and Chile (7.3, 5.1, and 4.6 deaths/100,000 people in 2016, respectively) [9].

The Latin American Renal Cancer Group (LARCG) is a multi-institutional, non-profit group whose database consists of data collected from 28 centers in Latin America and Spain [10]. We aim to describe a large cohort of non-metastatic RCC cases in our database and identify the demographic, clinical, and pathological prognostic factors for overall and cancer-specific survival.

\section{MATERIALS AND METHODS}

\section{Data source}

We developed a spreadsheet with fields for demographic, clinical, and pathological variables, and sent it to all member institutions of LARCG. In February 2016, 28 centers from eight countries filled this spreadsheet, resulting in the collection of data for 6,132 patients who underwent radical nephrectomy (RN) or partial nephrectomy (PN) from 1980 to 2016. Data were collected from patient charts and pathological reports from institutions in Argentina, Bolivia, Brazil, Chile, Mexico, Peru, Uruguay, and Spain. The Institutional Review Board approved this protocol and the study did not interfere with the treatment or follow-up of the involved patients. The protocol number is 2.478.489, CAAE: 71749917. 3.0000.5432.

\section{Patient selection}

We selected patients who underwent initial surgical treatment (RN or PN) due to RRC, staged as localized or locally advanced (pT1-4 Nx M0) in the pathological analysis. Patients with other concurrent malignancies (except for basal cell carcinoma or squamous cell carcinoma of the skin), or with severe comorbidities having a remaining life expectancy lower than six months, were excluded. We also excluded patients who underwent other treatments before the surgery (e.g., chemotherapy, radiotherapy, and immunotherapy), patients diagnosed with distant metastasis at presentation, and patients with inadequate collected data. 
The variables were age, gender, race, smoking status, Eastern Cooperative Oncologic Group (ECOG) scale, Karnofsky Performance Status, American Society of Anesthesiologists (ASA) score, symptoms at presentation, and preoperative anemia (hemoglobin $<10 \mathrm{~g} / \mathrm{dL}$ ). Patients were considered symptomatic at presentation if they had hematuria, local pain, palpable mass, paraneoplastic syndrome, neurological symptoms, acute onset varicocele, and constitutional alterations, such as weight loss, fatigue, and fever. The pathological variables included the histological subtype, TNM classification by the American Joint Committee on Cancer (AJCC) (2010) staging system, tumor size, positive surgical margins (PSM), nuclear grade (low or high grade), histologic tumoral necrosis, sarcomatoid component, nodal metastasis $(\mathrm{N}+)$, and multifocality or bilaterality. Histological subtype was defined according to the International Society of Urological Pathology (ISUP) Vancouver classification system (2012) [11]. Microvascular invasion (MVI) was considered positive when neoplastic emboli were evidenced in the vascular structures by microscopy $(400 \times-1,000 \times)$.

Follow-up was established from the date of surgery to the date of death or the latest follow-up. There was no central pathology review (except for the Brazilian cases). Treatment indications and followup routine were determined at the discretion of each center. The authors used a multiple imputation only for variables with a limited proportion of missing data, by applying the method proposed by Rubin [12].

Considering that large databases may present missing data, and decrease the precision of multivariate analyses, a multiple imputation technique was used [13]. The data were assumed to be missing completely at random (MCAR) and a method of predictive mean machine (PMM) was adopted [14]. Variables with more than $50 \%$ of missing data and non-attributable characteristics (e.g., race, and histological subtype) were not submitted to the imputation method. This method was used for the following variables: Pathological staging (20\% of missing data), anemia ( $21 \%$ of missing data), peri-renal fat invasion (24\% of missing data), smoking status (32\% of missing data), microvascular invasion (40\% of missing data), histological necrosis (41\% of missing data), weight (42\% of missing data), and ECOG performance status ( $44 \%$ of missing data).

\section{Statistical analysis}

Categorical variables were described as frequency and percentage in contingency tables. Continuous variables were grouped in categories. Kaplan-Meier curves were used to estimate the overall survival (OS) and cancer-specific survival (CSS). The subgroups were compared using the log-rank test in a univariate analysis. The Cox proportional hazards model was constructed for multivariate analysis of factors predicting the OS and CSS exceeding 120 months.

Table 1

Univariate analysis of demographic and clinical variables considering the distribution, and the number of deaths and their respective overall survival (OS) and cancer-specific survival (CSS) over 10 years

\begin{tabular}{|c|c|c|c|c|c|c|}
\hline Variable & Category & $\begin{array}{l}\text { Frequency } \\
\mathrm{N}(\%)\end{array}$ & $\begin{array}{l}\text { Global deaths } \\
\mathrm{N}(\mathrm{OS} \%)\end{array}$ & $p$-value & $\begin{array}{c}\text { Cancer-specific } \\
\text { deaths N (CSS\%) }\end{array}$ & $p$-value \\
\hline \multirow[t]{2}{*}{ Gender } & Male & $2,935(64.8)$ & $282(69.6)$ & 0.282 & $192(80.7)$ & 0.531 \\
\hline & Female & $1,573(35.2)$ & $144(69.3)$ & & $100(83.6)$ & \\
\hline \multirow[t]{3}{*}{ Age } & $<40$ & $333(7.4)$ & $15(89.2)$ & $<0.001$ & $13(89.5)$ & 0.067 \\
\hline & $40-59$ & $1,893(42)$ & $138(81.4)$ & & $116(80.2)$ & \\
\hline & $\geq 60$ & $2,282(50.6)$ & $265(69.9)$ & & $154(82.1)$ & \\
\hline \multirow[t]{2}{*}{ Race $(\mathrm{N}=\mathbf{2 , 8 8 4})$} & White & $2,371(82.2)$ & $274(58.0)$ & $<0.001$ & $171(76.5)$ & $<0.001$ \\
\hline & Non-white & $513(17.8)$ & $66(71.1)$ & & $60(79.1)$ & \\
\hline \multirow[t]{3}{*}{ Smoking } & Non-smoker & $2771(61.5)$ & $256(68.9)$ & 0.454 & $184(81.8)$ & 0.129 \\
\hline & Smoker & $547(12.1)$ & $127(67.2)$ & & $81(79.0)$ & \\
\hline & Former smoker & $1190(26.4)$ & $43(75.4)$ & & $27(87.5)$ & \\
\hline Signs and symptoms at diagnosis & & $2,656(58.9)$ & $326(63.3)$ & $<0.001$ & $258(74.2)$ & $<0.001$ \\
\hline \multirow[t]{2}{*}{ KPS } & $\leq 80$ & $637(14.1)$ & $128(48.4)$ & $<0.001$ & $98(58.3)$ & $<0.001$ \\
\hline & $>80$ & $3,871(85.9)$ & $298(72.2)$ & & $194(84.6)$ & \\
\hline \multirow[t]{2}{*}{ ECOG } & $0-1$ & $4,181(92.7)$ & $353(70.8)$ & $<0.001$ & $231(83.4)$ & $<0.001$ \\
\hline & $\geq 2$ & $327(7.3)$ & $73(49.8)$ & & $61(57.4)$ & \\
\hline \multirow[t]{2}{*}{ ASA } & $1-2$ & $3,629(80.5)$ & $293(70.5)$ & $<0.001$ & $204(82.8)$ & $<0.001$ \\
\hline & $\geq 3$ & $879(19.5)$ & $133(67.6)$ & & $88(78.8)$ & \\
\hline Anemia & & $1,092(24.2)$ & $174(69.1)$ & $<0.001$ & $129(76.3)$ & $<0.001$ \\
\hline
\end{tabular}

${ }^{*} p$-value $<0.05$ is considered statistically significant. KPS - Karnofsky Performance Status; ECOG - Eastern Cooperative Oncologic Group; ASA - American Society of Anesthesiologists. 
The results were described as hazard ratios (HR) and their respective $95 \%$ confidence intervals (CI). The analysis was conducted using IBM SPSS ${ }^{\circledR}$ software v.17 (IBM Corp. Armonk, NY, USA), and a 2-sided $p$-value $<0.05$ was considered statistically significant.

\section{RESULTS}

We analyzed cases from eight countries operated between 1980 and 2016, counting 5,670 patients with no metastases at presentation. Among them, 33.1\% (1,878 cases) were from Argentina, $18.9 \%$ (1,073 cases) from Brazil, $18.5 \%$ (1,050 cases) from Spain, and the others were from Chile (558 cases), Uruguay (458 cases), Mexico (274 cases), Peru (338 cases), and Bolivia (41 cases). For the survival analysis, we excluded 1,162 cases due to lack of follow-up data. A total of 4,508 patients met our inclusion criteria.

The follow-up time was 20 months ranged from 0 to 162 months, with a median of 20 months. The patients' ages varied from 18 to 95 years (median age: 60 years old), with a predominance of male patients $(64.8 \%)$. Table 1 represents the main clinicodemographic features.
According to the pathological analysis, clear cell RCC represented $66.7 \%$ of cases, followed by chromophobe RCC (13.7\%), and papillary RCC (5.2\%). Other subtypes (14.4\%) were unclassified, collecting duct carcinoma, Xp11 translocation subtype, and others. Relating to tumor sizes, lesions varied from $1.0 \mathrm{~cm}$ to $22.0 \mathrm{~cm}$. Furthermore, $72.3 \%$ of renal masses were $<7.0 \mathrm{~cm}$.

Regarding locally advanced diseases, we found peri-renal fat invasion in 554 cases (12.3\%), renal vein thrombus in 348 cases $(7.7 \%)$, and inferior vena cava invasion in 176 cases $(3.9 \%)$. We found lymph node metastasis in 131 cases (2.9\%). However, $40.1 \%$ of the pathological reports had no information regarding nodal disease ( $\mathrm{pNx}$ ), corresponding to the patients who underwent PN or RN with no lymphadenectomy. Table 2 represents the main pathological data.

At the time of this analysis, 3,259 patients $(72.2 \%)$ were alive without disease, and $356(7.6 \%)$ had local recurrence. Overall death occurred in 426 patients (7.5\%), and 292 (6.5\%) had cancer-related death. There was a lack of information for 154 (3.4\%) alive patients and $24(0.5 \%)$ dead patients.

Table 2

Univariate analysis of pathological variables considering the distribution, and the number of deaths and their respective overall survival (OS) and cancer-specific survival (CSS) over 10 years

\begin{tabular}{|c|c|c|c|c|c|c|}
\hline Variable & Category & $\begin{array}{l}\text { Frequency } \\
\mathrm{N}(\%)\end{array}$ & $\begin{array}{c}\text { Global deaths } \\
\mathrm{N}(\mathrm{OS} \%)\end{array}$ & $p$-value* & $\begin{array}{c}\text { Cancer-specific } \\
\text { deaths N }(\mathrm{CSS} \%)\end{array}$ & $p$-value* \\
\hline \multirow[t]{8}{*}{ Histologic subtype $(\mathrm{N}=2,984)$} & Clear cell & $1,993(66.7)$ & $210(61.8)$ & 0.020 & $125(79.4)$ & 0.030 \\
\hline & Papillary type 1 & $142(4.7)$ & $16(70.1)$ & & $10(88.4)$ & \\
\hline & Papillary type 2 & $18(0.6)$ & $1(88.9)$ & & $1(88.9)$ & \\
\hline & Chromophobe & 409 (13.7) & $12(95.1)$ & & $7(97.5)$ & \\
\hline & Unclassified & $69(2.3)$ & $8(67.1)$ & & $5(77.0)$ & \\
\hline & TFE gene & $7(0.2)$ & $1(98.6)$ & & $1(98.6)$ & \\
\hline & Collecting duct & $34(1.1)$ & $0(100.0)$ & & $0(100.0)$ & \\
\hline & Others & $412(13.8)$ & $25(73.4)$ & & $15(92.4)$ & \\
\hline \multirow[t]{2}{*}{ Nuclear grade } & Low grade & $2,673(59.3)$ & $204(73.9)$ & $<0.001$ & $118(87.0)$ & $<0.001$ \\
\hline & High grade & $1,835(40.7)$ & $222(60.7)$ & & $174(72.2)$ & \\
\hline Tumoral necrosis & & $1,221(27.1)$ & $213(54.4)$ & $<0.001$ & $160(67.9)$ & $<0.001$ \\
\hline Sarcomatoid component $(\mathrm{N}=\mathbf{2 , 1 3 6 )}$ & & $43(2.0)$ & $13(0.0)$ & $<0.001$ & $10(61.6)$ & $<0.001$ \\
\hline Peri-renal fat invasion & & $554(12.3)$ & $142(39.6)$ & $<0.001$ & $115(53.7)$ & $<0.001$ \\
\hline Renal vein thrombus & & $348(7.7)$ & $68(50.3)$ & $<0.001$ & $53(64.8)$ & $<0.001$ \\
\hline IVC invasion & & $176(3.9)$ & $38(41.0)$ & $<0.001$ & $29(64.5)$ & $<0.001$ \\
\hline Microvascular invasion & & $635(14.1)$ & $107(56.6)$ & $<0.001$ & $88(65.9)$ & $<0.001$ \\
\hline Renal pelvis invasion $(\mathrm{N}=\mathbf{3 , 9 9 6})$ & & $339(8.5)$ & $53(57.5)$ & $<0.001$ & $40(80.7)$ & $<0.001$ \\
\hline Adrenal invasion $(\mathrm{N}=\mathbf{3 , 9 9 6})$ & & $97(2.4)$ & $20(50.4)$ & $<0.001$ & $17(82.5)$ & $<0.001$ \\
\hline \multirow[t]{3}{*}{ Tumor size } & $<4 \mathrm{~cm}$ & $1,569(34.8)$ & $98(74.7)$ & $<0.001$ & $55(96.5)$ & $<0.001$ \\
\hline & $4.1-7 \mathrm{~cm}$ & $1,689(37.5)$ & $126(70.7)$ & & $79(95.3)$ & \\
\hline & $>7 \mathrm{~cm}$ & $1,250(27.7)$ & $202(60.4)$ & & $158(87.4)$ & \\
\hline \multirow[t]{2}{*}{ pT stage } & $\mathrm{T} 1-\mathrm{T} 2$ & $3,733(82.9)$ & $266(92.9)$ & $<0.001$ & $164(86.2)$ & $<0.001$ \\
\hline & $\mathrm{T} 3-\mathrm{T} 4$ & $775(17.1)$ & $160(79.4)$ & & $128(61.1)$ & \\
\hline \multirow[t]{3}{*}{$\mathrm{pN}$ stage } & pNO & $2,571(57.0)$ & $223(91.3)$ & 0.206 & $157(81.8)$ & 0.072 \\
\hline & $\mathrm{pNx}$ & $1,806(40.1)$ & $168(90.7)$ & & 103 (83.6) & \\
\hline & $\mathrm{pN} 1$ & $131(2.9)$ & $35(73.3)$ & & $32(51.7)$ & \\
\hline Positive Surgical Margins $(\mathrm{N}=\mathbf{3 , 8 7 5})$ & & $136(3.5)$ & $114(84.6)$ & $<0.001$ & $19(86.2)$ & $<0.001$ \\
\hline
\end{tabular}

${ }^{*} p$-value $<0.05$ is considered statistically significant. IVC - Inferior vena cava. 
The 5-year OS and 10-year OS rates were $86.1 \%$ and $69.5 \%$, respectively. The median OS in elderly patients ( $>60$ years) was 99.9 months, which was significantly different from the group between 40 and 59 years old (106.8 months) and those under 40 years old (111.9 months). The 5-year and 10-year CSS rates were $89.9 \%$ and $81.8 \%$, respectively, and the median CSS was 109 months (107.8-110.3 months).

In the univariate analysis, OS and CSS were influenced by all the variables except gender, smoking, and non-grouped $\mathrm{pN}$ stage $(p>0.05)$. Age was not a predictor of CSS in the univariate analysis. When grouping $\mathrm{pN} 0$ and $\mathrm{pNx}$, there was a significant effect on OS and CSS (Tables 1 and 2).

Multivariate analysis was conducted with factors predicting 10-year OS (Table 3). Demographic and clinical predicting factors were age (HR: $2.978,95 \%$ CI: $2.038-5.269$ for elderly people $\geq 60$ years old), anemia (HR: 1.44, 95\% CI: 1.17-1.76; $p=0.001$ ), presence of symptoms at presentation (HR: 1.26, 95\% CI: $1.02-1.60 ; p=0.037)$, Karnofsky score $\leq 80$ (HR: 2.12, 95\% CI: 1.67-2.7; $p<0.001$ ), and ASA score $\geq 3$ (HR: $1.49,95 \%$ CI: $1.19-1.86 ; p<0.001$ ). The pathological factors were nodal metastasis (HR: 2.14, 95\% CI: $1.5-3.06 ; p<0.001)$, peri-renal fat invasion (HR: $2.12,95 \%$ CI: $1.7-2.65 ; p<0.001$ ), inferior vena cava (IVC) invasion (HR: $1.61,95 \%$ CI: $1.15-2.27 ; p=0.006)$, histologic tumoral necrosis (HR: $1.69,95 \%$ CI: $1.21-2.09 ; p<0.001)$, and tumor size $>7 \mathrm{~cm}$ (HR: $1.64,95 \%$ CI: $1.33-2.09 ; p<0.001$ ). The multivariate analysis of CSS, according to the demographic, clinical, and pathological features is described in Table 4.

\section{DISCUSSION}

In this study, we included data from 28 institutions in LA and Spain, and thus, this study is a unique initiative that can act as a foundation for future studies on RCC involving this population. Survival rates were notably high in this study (OS: 69.5\%; CSS: $81.8 \%$ ). The OS and CSS in this population were satisfactory and comparable with other international series. Some features that could justify these findings are the percentage of young patients under 60 years old, the increase in the life expectancy around the world, the predominance of patients classified as ASA $2(68.1 \%)$ and ASA $1(18.5 \%)$, and the rise of incidental tumors at the localized stage $(76.1 \%$ were pT1 or pT2) $[15,16]$. Nevertheless, the majority of patients had a good performance status. Only
$14.9 \%$ had a Karnofsky score <80, and less than $8 \%$ presented the ECOG score $\geq 2$. Regarding the pathological factors, nodal metastasis and high histological grade (grades III or IV) are adverse factors for OS and CSS $[3,17,18]$. In this series, the high nuclear grade was found in $40 \%$ of the cases, and the nodal disease occurred infrequently in only $3 \%$.

Gender was not a significant predictor in our analysis. However, recent studies within the past few decades suggest a better survival rate for women [17, 18]. Recently, for LA patients who underwent minimally invasive surgery, Secin et al. (2017) and Lee et al. (2012) demonstrated that the mortality and local recurrence rates in women are up to four times greater than in men, resulting in a controversy $[19,20]$.

Age impacts global mortality. However, some studies reported worse CSS related to younger patients [1, $15,16]$. In our univariate and multivariate analysis, age was not a significant predictor $(p=0.067)$. There are probably no biological differences in RCC among young and elderly patients in the population of our study.

The impact of ethnicity in cancer mortality is controversial. In our series, patients grouped as black or mulatto presented better OS and CSS rates (mean $\mathrm{OS}=104.4$ months vs. 99.4 months for the others), but this difference was not significant $(p=0.341)$. This group represented just $2 \%$ of the reported cases in our database. In a multi-ethnic population, there are no accurate interpretations to justify this data. Moreover, race information was absent in $36.1 \%$ of the cases. Data from the USA show similar rates for Hispanics and non-Hispanics. Black patients in the USA have demonstrated a faster decrease in mortality rates compared to white patients since the 1970s [7].

Nowadays, there is a tendency to offer active surveillance in localized masses for patients with multiple comorbidities (ASA $\geq 3$ ). Our group previously reported that this feature could be an adverse prognostic factor in RCC. ASA also seems to be associated with tumors with more aggressive pathological features [21]. In our study, ASA score impacted OS and CSS in the univariate analysis. In the multivariate analysis, the ASA score persisted as an independent prognostic factor for 10-year OS and the segments at 36 or 60 months, but not for CSS.

In the literature, anemia can be related to the worst prognosis. The absolute hematocrit level is associated with other factors, such as nutrition and diet, medications in use, external bleeding, hematologic diseases, and genetics [22]. We chose the cut-off point of hemoglobin lower than $10 \mathrm{~g} / \mathrm{dL}$. Anemia was con- 
Table 3

Multivariate analysis of selected variables in overall mortality risk for non-metastatic RCC ( $N=4,508$ patients)

\begin{tabular}{lcccc}
\hline Variable & Category & HR & $95 \%$ CI & $p$-value* \\
\hline Age & $<40$ & Ref. & - & - \\
& $40-59$ & 2.013 & $1.011-3.012$ & $\mathbf{0 . 0 2 4}$ \\
& $\geq 60$ & 2.978 & $2.038-5.269$ & $\mathbf{0 . 0 0 1}$ \\
Anemia & & 1.991 & $0.226-17.539$ & 0.535 \\
& No & Ref. & - & - \\
Signs and symptoms at diagnosis & Yes & 1.437 & $1.170-1.765$ & $\mathbf{0 . 0 0 1}$ \\
& No & Ref. & - & - \\
ASA & Yes & 1.257 & $1.016-1.581$ & $\mathbf{0 . 0 3 7}$ \\
& $1-2$ & Ref. & - & - \\
KPS & $\geq 3$ & 1.486 & $1.187-1.861$ & $<\mathbf{0 . 0 0 1}$ \\
& $>80$ & Ref. & - & - \\
IVC invasion & $\leq 80$ & 2.122 & $1.673-2.690$ & $<\mathbf{0 . 0 0 1}$ \\
Peri-renal fat invasion & No & Ref. & - & - \\
& Yes & 1.614 & $1.146-2.273$ & $\mathbf{0 . 0 0 6}$ \\
Tumoral necrosis & No & Ref. & - & - \\
& Yes & 2.121 & $1.699-2.647$ & $<\mathbf{0 0 1}$ \\
Tumor size & No & Ref. & - & - \\
& Yes & 1.694 & $1.210-2.092$ & $<\mathbf{0 . 0 0 1}$ \\
pN stage & $\leq 7 \mathrm{~cm}$ & Ref. & - & - \\
& $>7 \mathrm{~cm}$ & 1.644 & $1.333-2.092$ & - \\
\hline
\end{tabular}

${ }^{*} p$-value $<0.05$ is considered statistically significant. ASA - American Society of Anesthesiologists; IVC - Inferior Vena Cava; KPS - Karnofsky Performance Score.

Table 4

Multivariate analysis of selected variables in cancer-specific mortality risk for non-metastatic RCC (N=4,508 patients)

\begin{tabular}{lcccc}
\hline Variable & Category & HR & $95 \%$ CI & $p$-value* \\
\hline Anemia & No & Ref. & - & - \\
& Yes & 1.498 & $1.172-1.917$ & $\mathbf{0 . 0 0 1}$ \\
Signs and symptoms at diagnosis & No & Ref. & - & - \\
& Yes & 1.818 & $1.302-2.538$ & $\mathbf{0 . 0 0 1}$ \\
ECOG & $0-1$ & Ref. & - & - \\
& $\geq 2$ & 1.654 & $1.121-2.440$ & $\mathbf{0 . 0 1 1}$ \\
KPS & $>80$ & Ref. & - & - \\
& $\leq 80$ & 2.065 & $1.649-2.902$ & $<\mathbf{0 . 0 0 1}$ \\
Microvascular invasion & No & Ref. & - & - \\
& Yes & 1.413 & $1.080-1.847$ & $\mathbf{0 . 0 1 2}$ \\
Peri-renal fat invasion & No & Ref. & - & - \\
& Yes & 2.130 & $1.626-2.789$ & $<\mathbf{0 . 0 0 1}$ \\
Tumoral necrosis & No & Ref. & - & - \\
Tumor size & Yes & 1.773 & $1.370-2.294$ & $<\mathbf{0 . 0 0 1}$ \\
Nuclear grade & $\leq 7 \mathrm{~cm}$ & Ref. & - & - \\
& $>7 \mathrm{~cm}$ & 2.023 & $1.574-2.601$ & $<\mathbf{0 . 0 0 1}$ \\
pN stage & Low grade & Ref. & - & - \\
& High grade & 1.399 & $1.090-1.796$ & $\mathbf{0 . 0 0 8}$ \\
\hline
\end{tabular}

${ }^{*} p$-value $<0.05$ is considered statistically significant. ECOG - Eastern Cooperative Oncology Group Performance Status; KPS - Karnofsky Performance Scale.

sidered as an adverse predictor for $\mathrm{OS}(\mathrm{HR}=1.43)$ and CSS $(\mathrm{HR}=1.45)$.

Smoking is a recognized risk factor for RCC, but there is no consensus on whether it works as a prognostic factor. In some studies, smoking is associated with worst survival, but this is a controversial issue [23-25]. In this series, former smokers had lower
OS and CSS rates, but this was not statistically significant. We were unable to report whether former smokers in this study had a higher tobacco exposure than active smokers. Further efforts will be required to elucidate this issue.

The predominance of renal masses at the initial stages may explain the fact that pT staging was not a 
significant predictor, even after classifying the stages into two groups (pT1-pT2 and pT3-pT4). The isolate analysis of pT staging is not sufficiently accurate to determine prognosis. Nonetheless, the assumption of tumor size greater than $7 \mathrm{~cm}$ as an independent prognostic factor corroborated the findings of other studies $[26,27]$. Other factors, such as nuclear grade and node disease are also important. Similar to the results of the European Organization for Research and Treatment of Cancer (EORTC) trial conducted by Blom et al. (2009), we found nodal metastasis in 3\% of the cases (vs. $4 \%$ in the EORTC trial) [28]. Nowadays, regional lymphadenectomy is not a routine procedure and has no defined templates, particularly in nephronsparing surgeries. In our series, $\mathrm{pN}+$ cases presented OS and CSS rates around $73 \%$ and $75 \%$, respectively. Other series reported rates lower than $30 \%$ over five years $[1,3,29]$. Usually, almost $50 \%$ of $\mathrm{pN}+$ patients present concomitant distant metastasis. We did not consider patients with distant metastasis, so this fact could have contributed for these better survival rates.

Despite the limitations and recent recommendations about nuclear grade [11], we selected classifications of the low and high nuclear grades. A high nuclear grade evidenced a higher cancer mortality (HR:1.399, 95\% CI: 1.090-1.796). However, nuclear grade did not persist as an independent predictor in a truncated analysis at 36 or 60 months (data not shown). The histologic tumoral necrosis increased the global and cancer-specific mortality by $65 \%$ to $70 \%$. Intratumoral necrosis was originally described as a prognostic factor for clear cell RCC [30]. In our series, we had a predominance of clear cell RCC, but about one-third of cases with tumoral necrosis had other histologic subtypes. Necrosis can be related to a high cellular proliferation index leading to intratumoral hypoxia. This issue, particularly in non-clear cell subtypes, needs further investigations [31]. In the same way, the sarcomatoid component impacted OS and CSS rates. Of the 2,876 cases available for this information, we found $3 \%$ with a sarcomatoid component.

The most important predictor for global and cancer-specific mortality in multivariate analysis was peri-renal fat invasion (HR: 2.121, 95\% CI: 1.699-2.647; and HR: 2.107, 95\% CI: 1.681-3.579, respectively). If the adipose tissue is involved, the tumor cells are in intimal contact with microvasculature and lymphatics vessels in peri-renal tissue, favoring the metastatic dissemination [32]. The concomitance of fat invasion and other adverse factors, such as high nuclear grade, sarcomatoid component, nodal metastasis, or venous invasion leads to worse survival rates $[33,34]$. In some series, peri-renal invasion is not an independent prognostic factor for OS or CSS. In a series from our group with 511 metastatic patients undergone nephrectomy, the peri-renal fact invasion was also an independent prognostic factor for adverse OS and CSS [35]. In our view, this pathologic feature seems to be important and requires more investigations.

The adverse prognostic role of renal sinus invasion occurring isolated or in association with peri-renal fat invasion has been investigated. The renal sinus presents profuse microcirculation close to the hilar and lymphatic vessels [36]. Renal sinus invasion was not studied because this information was not available in many cases of our database.

We found that microvascular invasion (MVI) was an adverse predictor in the univariate and multivariate analysis for OS and CSS. Although this factor has already been demonstrated in previous studies, the ISUP/WHO classification did not require a mandatory description on the pathological reports $[11,37]$. MVI is a prognostic factor in other urological malignancies, and its detection can be made by expert pathologists with no significant increase in institutional costs. We believe that this information should be regularly incorporated in pathological reports.

Positive surgical margins (PSM) are considered risk factors for local recurrences, mainly in patients who undergo PN $[38,39]$. However, the impact on OS and CSS is debated. In this study, the survival rates were about 10 months lower than those of patients with negative margins. PSM was a significant predictor only in the univariate analysis, which is consistent with the findings reported in the literature.

Interestedly, we detected a high proportion of chromophobe RCC in this population (16\%). The literature usually reports a proportion between $6 \%$ and $10 \%$ [40]. Moreover, the survival rates of chromophobe RCC were better, which is consistent with this histologic subtype. A possible explanation is that these cases could be mistaken as oncocytic renal neoplasms [11].

We can find some limitations in our study. First, this is a retrospective multicentric study with patients treated at different times. It demands efforts from all the involved centers to provide and review reliable data, besides the lack of information of a few variables. Second, there was not a central pathological review (except in Brazilian cases). However, these patients were treated on regional referral centers, and the majority of pathologic evaluations were 
performed by skilled uro-pathologists reflecting the reality of treatment of RCC in LA tertiary care centers. Anyway, we aim to validate these findings with further central pathology review and future studies from the group. Despite such limitations, we believe that this study contributes to knowledge regarding RCC and brings the opportunity for more deep investigations related to the significant prognostic factors identified in this series.

\section{CONCLUSIONS}

This cooperative project aggregated a large, representative RCC database. This database can be a foundation for several other studies in the research area. Our findings agreed with series results from developed countries. The presence of signs and symptoms at presentation, anemia, KPS $\leq 80$, IVC invasion, nodal disease, tumoral necrosis, large tumor size, ASA $>3$, older adults $>60$ years old, and peri-renal fat invasion interferes with 10 -years OS. Furthermore, symptomatic patients, anemia, ECOG $\geq 2$, KPS $\leq 80$, nodal disease, tumoral necrosis, MVI, high nuclear grade, large tumors, and peri-renal fat invasion are independent prognostic factors for 10years CSS. We emphasize that ASA and peri-renal fat invasion as prognostic factors deserve further study. Additionally, information regarding MVI should be incorporated in pathological reports.

\section{ACKNOWLEDGMENTS}

We thank all the members of LARCG who directly or indirectly contributed to make this project feasible. Continual research projects and humanitarian actions can help to diminish disparities across the globe.

\section{CONFLICT OF INTEREST}

The authors have no conflict of interest to report.

\section{SUPPLEMENTARY MATERIAL}

We included as supplementary material the graphics of univariate analysis related to the overall survival and cancer-specific survival of the studied variables.

The supplementary material is available in the electronic version of this article: http://dx.doi. org/10.3233/KCA-190068.

\section{REFERENCES}

[1] Thrasher JB, Paulson DF. Prognostic factors in renal cancer. Urol Clin North Am. 1993;20(2):247-62.

[2] Kontak JA, Campbell SC. Prognostic factors in renal cell carcinoma. Urol Clin North Am. 2003;30(3):467-80.

[3] Campbell SC, Lane B. Malignant renal tumors. In: Wein A, Kavoussi L, Novick A, Partin A, Peters C, editors. Campbell-Walsh Urology. 11th ed. Philadelphia: Elsevier; 2016. p. 1314-65.

[4] Siegel RL, Miller KD, Jemal A. Cancer statistics, 2019. CA Cancer J Clin. 2019;69(1):7-34.

[5] Howlader N, Noone A, Krapcho M, Garshell J, Miller D, Altekruse S, et al. SEER Cancer Statistics Review, 19752012 [homepage on the Internet]. Bethesda; 2015. Available from: https://seer.cancer.gov/archive/csr/1975_2012/

[6] Bray F, Ferlay J, Soerjomataram I, Siegel RL, Torre LA, Jemal A. Global cancer statistics 2018: GLOBOCAN estimates of incidence and mortality worldwide for 36 cancers in 185 countries. CA Cancer J Clin. 2018;68(6):394-424.

[7] Scelo G, Larose TL. Epidemiology and Risk Factors for Kidney Cancer. J Clin Oncol.2019;36(36):3574-82.

[8] Znaor A, Lortet-Tieulent J, Laversanne M, Jemal A, Bray F. International variations and trends in renal cell carcinoma incidence and mortality. European Urology. 2015;67:51930.

[9] International Agency for Research on Cancer, Mortality Database. [homepage on the Internet]. World Health Organization, Department of Information, Evidence and Research. Available from: https://wwwdep.iarc.fr/WHOdb/WHOdb.htm

[10] Zequi S de C, Clavijo DA. The creation, development and diffusion of the LARCG latin american renal cancer group. Int Braz J Urol. 2017;43(1):3-6.

[11] Srigley JR, Delahunt B, Eble JN, Egevad L, Epstein JI, Grignon D, et al. The International Society of Urological Pathology (ISUP) Vancouver Classification of Renal Neoplasia. Am J Surg Pathol. 2013;37(10):1469-89.

[12] Rubin D. Multiple imputation for nonresponse in surveys. 1st ed. New York: Wiley-Blackwell; 1987.

[13] Fiero MH, Huang S, Oren E, Bell ML. Statistical analysis and handling of missing data in cluster randomized trials : a systematic review. Trials. 2016;17(72):1-10.

[14] Buuren S, Groothuis-Oudshoorn K. Mice: Multivariate imputation by chained equations in R. J Stat Softw. 2011;45:1-67.

[15] Daugherty M, Bratslavsky G. Compared with radical nephrectomy, nephron-sparing surgery offers a long-term survival advantage in patients between the ages of 20 and 44 years with renal cell carcinomas $(\leq 4 \mathrm{~cm})$ : an analysis of the SEER database. Urol Oncol. 2014;32(5):549-54.

[16] Wang L, Hughes I, Snarskis C, Alvarez H, Feng J, Gupta GN, Picken MM. Tumor enucleation specimens of small renal tumors more frequently have a positive surgical margin than partial nephrectomy specimens, but this is not associated with local tumor recurrence. Virchows Arch. 2017;470(1):55-61.

[17] Onishi T, Oishi Y, Goto H, Yanada S, Abe K. Gender as a prognostic factor in patients with renal cell carcinoma. BJU Int. 2002;90(1):32-6.

[18] Rampersaud EN, Klatte T, Bass G, Patard J-J, Bensaleh K, Böhm M, et al. The effect of gender and age on kidney cancer survival: younger age is an independent prognostic factor in women with renal cell carcinoma. Urol Oncol. 2014;32(1):30.e9-13. 
[19] Secin FP, Castillo OA, Rozanec JJ, Featherston M, Holst $\mathrm{P}$, Milfont JCA, et al. American Confederation of Urology (CAU) experience in minimally invasive partial nephrectomy. World J Urol. 2017;35(1):57-65.

[20] Lee S, Jeon HG, Kwak C, Kim HH, Byun S-S, Lee SE, Lee E. Gender-specific clinicopathological features and survival in patients with renal cell carcinoma (RCC). BJU Int. 2012;110(2 Pt 2):E28-33.

[21] de Cássio Zequi S, de Campos ECR, Guimarães GC, Bachega W, da Fonseca FP, Lopes A. The use of the American Society of Anesthesiology Classification as a prognostic factor in patients with renal cell carcinoma. Urol Int. 2010;84(1):67-72.

[22] Magera JS, Leibovich BC, Lohse CM, Sengupta S, Cheville JC, Kwon ED, Blute ML. Association of abnormal preoperative laboratory values with survival after radical nephrectomy for clinically confined clear cell renal cell carcinoma. Urology. 2008;71(2):278-82.

[23] Keizman D, Gottfried M, Ish-Shalom M, Maimon N, Peer A, Neumann A, et al. Active smoking may negatively affect response rate, progression-free survival, and overall survival of patients with metastatic renal cell carcinoma treated with sunitinib. Oncologist. 2014;19(1):51-60.

[24] Xu Y, Qi Y, Zhang J, Lu Y, Song J, Dong B, et al. The impact of smoking on survival in renal cell carcinoma: a systematic review and meta-analysis. Tumour Biol. 2014;35(7):6633-40.

[25] Sunela KL, Kataja MJ, Kellokumpu-Lehtinen P-LI. Influence of body mass index and smoking on the long-term survival of patients with renal cell cancer. Clin Genitourin Cancer. 2013;11(4):458-64.

[26] Bedke J, Pritsch M, Buse S, Jakobi H, Elsaesser K-H, Pahernik S, et al. Prognostic stratification of localized renal cell carcinoma by tumor size. J Urol. 2008;180(1):62-7.

[27] Lam JS, Klatte T, Patard J-J, Goel RH, Guillè F, Lobel $\mathrm{B}$, et al. Prognostic relevance of tumour size in T3a renal cell carcinoma: a multicentre experience. Eur Urol. 2007;52(1):155-62.

[28] Blom JHM, van Poppel H, Maréchal JM, Jacqmin D, Schröder FH, de Prijck L, et al. Radical nephrectomy with and without lymph-node dissection: final results of European Organization for Research and Treatment of Cancer (EORTC) randomized phase 3 trial 30881. Eur Urol. 2009;55(1):28-34.

[29] Pantuck AJ, Zisman A, Dorey F, Chao DH, Han K-R, Said J, et al. Renal cell carcinoma with retroperitoneal lymph nodes: role of lymph node dissection. J Urol. 2003;169(6):2076-83.
[30] Frank I, Blute M, Cheville J, Lohse C, Weaver A, Zincke $\mathrm{H}$. An outcome prediction model for patients with clear cell renal cell carcinoma treated with radical nephrectomy based on tumor stage, size, grade and necrosis: the SSIGN score. J Urol. 2002;168(6):2395-400.

[31] Sengupta S, Lohse CM, Leibovich BC, Frank I, Thompson RH, Webster WS, et al. Cancer. 2005;104(3):511-20.

[32] Jeon H, Jeong I, Kwak C, Kim H, Lee S, Lee E. Reevaluation of renal cell carcinoma and perirenal fat invasion only. J Urol. 2009;182(5):2137-43.

[33] Wagner B, Patard J-J, Méjean A, Bensalah K, Verhoest G, Zigeuner R, et al. Prognostic value of renal vein and inferior vena cava involvement in renal cell carcinoma. Eur Urol. 2009;55(2):452-9.

[34] da Costa WH, Moniz RR, da Cunha IW, Fonseca FP, Guimaraes GC, de Cássio Zequi S. Impact of renal vein invasion and fat invasion in pT3a renal cell carcinoma. BJU Int. 2012;109(4):544-8.

[35] American Urological Association Abstracts - Annual Meeting 2017 [homepage on the Internet]. Abreu D, Gueglio G, Garcia P, da Costa W, Beltrame D, Zuñiga A. Mp16-17 outcomes in over 4,000 patients with renal cell carcinoma from the latin american renal cancer group (LARCG): a focus on metastatic disease. p. 197:e186. Available from: http://www.aua2017.org/abstracts/

[36] Bedke J, Buse S, Pritsch M, Macher-goeppinger S, Schirmacher P, Haferkamp A, Hohenfellner M. Perinephric and renal sinus fat infiltration in pT3a renal cell carcinoma : possible prognostic differences. BJU Int. 2008;1349-54.

[37] Gonçalves PD, Srougi M, Dall'lio MF, Leite KRM, Ortiz V, Hering F. Low clinical stage renal cell carcinoma: relevance of microvascular tumor invasion as a prognostic parameter. J Urol. 2004;172(2):470-4.

[38] Steinestel J, Steffens S, Steinestel K, Schrader AJ. Positive surgical margins in nephron-sparing surgery: risk factors and therapeutic consequences. World J Surg Oncol. 2014;12:252.

[39] Marchiñena PG, Tirapegui S, Gonzalez IT, Jurado A, Gueglio G. Positive surgical margins are predictors of local recurrence in conservative kidney surgery for pT1 tumors. Int Braz J Urol. 2018;44(3):475-82.

[40] Haake SM, Rathmell WK. Renal cancer subtypes: Should we be lumping or splitting for therapeutic decision making? Cancer. 2017;123(2):200-9. 